Preventive Care in Nursing and Midwifery Journal

2018; 8(3): 42-50

\title{
Effect of Structured Nursing Education Programs in Prevention of Admitted Patients' Phlebitis
}

\author{
Baghaei $\mathrm{R}^{1} \mathbb{i}$, Khalkhali $\mathrm{HR}^{2} \mathbb{i}, \underline{\text { Rezaeifar } \mathrm{P}^{3 *}}$ \\ ${ }^{1}$ Department of Nursing, Associate Professor, School of Nursing and Midwifery, Urmia University of Medical Sciences, Urmia, Iran \\ ${ }^{2}$ Department of Biostatistics and Epidemiology, Associate Professor, School of Medicine, Urmia University of Medical Sciences, Urmia, Iran \\ ${ }^{* 3}$ Department of Critical Care Nursing, School of Nursing and Midwifery, Urmia University of Medical Sciences, Urmia, Iran
}

*Corresponding Author: Department of Critical Care Nursing, School of Nursing and Midwifery, Urmia University of Medical Sciences, Urmia, Iran

Email: rezaeifar.p@gmail.com

Received: 2 Dec 2019 Accepted: 14 Jan 2020

\begin{abstract}
Background: In the hospitalization wards where phlebitis has an incidence and accounts for the most serious complications of environmental fluid therapy.

Objectives: This study aimed to determine the effect of structured nursing education programs in prevention of admitted patients' phlebitis.

Methods: In this quasi-experimental study in which the post-test design with control and intervention group was used, 400 patients were randomly divided into two groups of 200. Data were collected by questionnaire including demographic questions and Jackson's Visual Infusion Phlebitis (VIP) scale was used to evaluate the complications of peripheral vascular catheter (phlebitis). The findings were analyzed by SPSS 25 software.

Results: The mean score of phlebitis incidence in the hospital wards, whose nurses that had undergone such trainings, was significantly decreased $(\mathrm{p}<0.001)$ compared to the mean score of phlebitis occurrence in the wards, whose nurses represented the control group and had taken part in no such training programs. Moreover, the mean score of intensity of Phlebitis complications in the wards, whose nurses that were members of the experimental group, significantly decreased $(p<0.001)$ compared to the mean score of phlebitis intensity among patients of the wards whose nurses represented the control group.

Conclusion: The findings of this study testify that holding a structured nursing education programs will be effective in checking the incidence of phlebitis and its complexity among the patients hospitalized in Imam Khomeini Hospital in Mahabad.
\end{abstract}

Keywords: structured care training, intravenous catheter, complications, phlebitis, nurse

\section{Introduction}

More than 80 to 90 percent of the patients nowadays hospitalized receive intravenous injections for getting treated. Moreover, beyond 500 million peripheral venous catheters are yearly implanted [1]. Intravenous catheter insersion is the most prevalent invasive method practiced in hospitals. That's considered the best or only option, however [2]. That's highly risky [3]. The access to the intravenous system through catheter placement is proved to lead to numerous complications, alike any other methodology. The most important such methods used for the purpose can be fluid leakage, phlebitis, fluid accumulation in the body, infection, and bleeding of the injection position. Phlebitis is regarded the most customary complication of all and the most dangerous problem resulting from the phenomenon is infection [4].

Phlebitis jeopardizes the patient's health, prolonging the period of hospitalization. The following problems come as a result: Infections 
and less patient comfort and consequently inflicting soaring cost on the patient and the Medicare center [5]. The following factors raise the risk of phlebitis and the venous infection: Factors relating to the demographic features of the patient (age, sex and background disease); characteristics of catheter (type, type of dressing, type of vein injection, anatomic location of the vein, how to prepare a vein for venipuncture, the time from venipuncture). Add to the list the skill and experience of the person responsible for venipuncture. Other factors like old age, being female, neutropenia, malnutrition, immune system weakness, circulatory dysfunction and peripheral neuropathy are also influential in incidence of phlebitis [6]. The most important factor leading to phlebitis is the shelf life of catheter. Phlebitis is most probable occurring within times beyond 48 hours [7]. Jackson's Phlebitis Scale (JPS) classifies phlebitis into 4 degrees.

Jackson's Phlebitis Scale (VIP):

\begin{tabular}{cl}
\hline degree & \multicolumn{1}{c}{ Symptoms } \\
\hline 0 degree & IV site appears healthy \\
\hline \multirow{3}{*}{ degree } & One of the following is evident \\
& $\begin{array}{l}\text { Slight pain near IV site } \\
\text { Slight redness near IV site }\end{array}$ \\
\hline \multirow{2}{*}{ degree } & Two of the following are evident \\
& Pain at IV site \\
& Erythema \\
& Swelling \\
\hline \multirow{3}{*}{ degree } & All of the following signs are evident and extensive \\
& Pain along the path of cannula \\
& Erythema \\
& Induration \\
\hline \multirow{4}{*}{ degree } & All of the following signs are evident and extensive \\
& Pain along the path of cannula \\
& Erythema \\
& Induration \\
& Palpable venous cord
\end{tabular}

Phlebitis of one to 63 percent is reported in California [8]. American Nurses Association considers five percent and/or less than the percentage as acceptable level of phlebitis incidence: This testifies the fact that phlebitis eruption is inevitable [9]. Furthermore, the rate of mortality as a result of cuthether infection is 20 percent and hospitalization prolongation as a result is almost one week with extra cost of $\$$ 3,700 [10].

As for Iran, phlebitis is said to be present by $69 \%$ in hospitals of the city of Sanandaj, by $88 \%$ Isfahan and by $65 \%$ in Zanjan [11]. In the 1950s, peripheral catheters survived less than 24 hours on the average, while in the 1970s between 24 and 48 hours, and today between 48 and 96 hours [12]. Maximum period for phlebitis incidence in Tehran hospitals is reported between 24 and 48 hours just following insersion of catheter [13].

Phlebitis is classified into three types: Mechanical, chemical and bacterial. The mechanical phlebitis occurs as a result of the intravenous catheter corrusion; prolongation of venous catheter insersion; catheter being larger in size than vein diameter; and insersion of the venous catheter where joint flexion is present; this is while, chemical phlebitis comes as a result of passage of intravenous medications and infused fluids. That is closely related to manifestation of the $\mathrm{pH}$ plus phlebitis, osmolality of materials, speed of infusion and incompatibility of solutions $[14,15]$. On the other hand, bacterial phlebitis is the result of bacteria colonization at the peripheral catheterization site in consequence of lack of hands' hygiene, any shortcoming in checking the instruments linked to catheter, and substandard clinical care in the course of medication and receipt of fluids and necessary supplements [16]. Nurses are suggested that the best kind of treatment in the cases of chemical, mechanical and bacterial phlebitis is to prevent their incidence $[17,6]$. To avoid the phenomenon, the nurses are 
recommended to repeatedly check the position angiocut is inserted and think of changing the location of placement upon observing the first and early symptoms like redness, tenderness and inflammation are observed [18,9].

As the bodies responsible for others' health, nurses are advised to enhance their knowledge and skills and get updated to deliver standard care in different phases of medication care, including insersion and change of cuthether or in the period the device is placed in the body. In general, qualtiative improvement of services, lowering expendictures, upgrading social health standards and trying to bring national standards to the level of international standards should be regarded as advantages of implementing guidelines in the medication centers. Following guidelines should be interpreted as a sort of consensus in carrying out procedures. That will raise logical measures and minimize errors. That will also offer a definite standard for care, which will in fact provide an environment for learning, while preparing the ground for equal care [19]. One of the kinds of edcation that can be provided in that domain is structured education. A structured nursesing education programs, provided within framework of the clinical guidelines of classified and developed information, will serve promotion of nursing services and clinical skills [20]. The structured learning method has been introduced and influenced more than half a century ago. Reaches and enjoys high research support. Structured training is an idea raised in the past half a century, distinguished as the most effective method among all. The issue is well supported by research. Structured education has stages like a ladder, indicating how the learners would contribute to and be recruited for the sake of education. This ladder has eight different kinds of steps (manipulation, decoration, symbolic participation, informed learner, the learner as a counseler, involvement of the learners in decision makings, the initiator learner and a guide to decision makings, and getting teachers involved in the decision making). The higher the learners ascend in the ladder, the more participant they will have in the process of education [21].

Regarding excessive use of the intravenous catheterization and spread of certain related complications, resulting from wrong conduct of nurses and their failure to observe related standards, a structured nursing education programs needs to be designed in conformity with related clinical guidelines [22]. Hence, the study at hand tries to address the following question: "Is structured nursing education program effective in checking phlebitis occurrence among the admitted patients?"

\section{Methods}

This study is quasi-experimental in nature, carried out through collection of descriptive data from a post-test, involving two control and experimental groups. The statistical population were all the patinets admitted to the surgery and internal medicine wards in Mahabad Hospital. The data were obtained from the participants from October 2018 to January 2018. Initially, the researcher obtained permission from university and the Ethics Committee with the ethics code being IR.UMSU.REC.1397.045. The researcher then referred to the environment where the research was to be done and made necessary arrangements with the nursing office and other related authorities.

A total of 400 patients, admitted to the surgery and internal medicine wards of Imam Khomeini hospital of Mahabad, were drawn as samples through the availability sampling method and joined the study. The criteria of sampling were as follows: 1 . The patient's signing informed consent for participation in this study; his/her consciousness and cooperation while the research project was underway 2) No addiction (confirmed so by related tests), 3) Usability of the patient's upper limb for intravenous catheterization 4) The patient's insensitivity to any drug or adhesive; the information was gained through questioning the patient, 5) No precedence of phlebitis in the area intravenous catheter (Angiocut) was to be inserted 6) having a healthy skin where the catheter was to be placed, 7) Not having any vascular disease or any illness that involved the musculoskeletal system and not having diabetes and the infectious, skin and peripheral vascular diseases such as lupus and sclerosis, 8) Having no fever or any symptoms of infection, 9) Having no co-occurrent kinds of treatment such as radiation therapy, 10) The patients falling within the age group of 20 to 50 . The criteria for discarding the non-qualified were as follows: The subjects' failure to fill up the 
demographic information and the phlebitis registration forms; non-willingness of the patient or his/her family to continue contribution to the research study; furthermore, the patient sample was discarded from the study when observing any skin or seasonal allergies.

The instruments for collection of the demographic information was the demographic questionnaire and peripheral vascular catheter complication (phlebitis) questionnaire. To study severity of phlebitis, Jackson's phlebitis scale (VIP) was used.

To assess validity of the forms, content validity methodology was used. Once corrected and confirmed by the superviser and the reader, the form was given to 10 conent experts in Urmia School of Nursing and Midwifery to judge them and offer necessary comments for its improvement. Then validity of the instrument was confirmed. Furthermore, reliability of the demographic information form was approved because its questions were objective and were repeatedly used in other studies. Three conent experts were asked to comment and their triangulated consensus was taken as the criteria for approval of the reliability of the observation forms. The researcher filled up the forms for 15 people in the research centers and then correlation among the scores was estimated. Three investigators then confirmed the process through the Pierson correlation coefficient formula.

Prior to intervention, the researcher, in charge of collecting the filled-up questionnaires, frequently referred to related wards in coordination with those in charge of the wards in order to monitor questionnaire completion during the working shifts. Those in charge of the wards were requested to provide nurses in their ward with necessary information and goals of the research. Furtheremore, the nurses, who were not willing to take part in this research, were asked to announce the issue so as to be discarded. To collect the data, indirect (invisible) observation method was used through an observation checklist. To raise the precision and accuracy of the data, indirect observation was preferred and the nurses under observation were not informed of the issue, hence avoiding any bias. To observe ethics, nursing directors and chief nurses had already been briefed on the subject and the methodology of the research. They were requested to provide the nurses taking part in this study on the given information. The researchers then brought the environment under initial examination to be ensured of feasibility of conduction of the project there. After signing the informed consent, the nurses in the internal medicine and surgery wards of Imam Khomeini Hospital in the city of Mahabad were randomly assigned into the experimental and control groups.

In line with the structured nurse education program, the experimental group was subdivided into four small 10-member groups in the intervention phase and nurses took part in the training sessions, characterized by critical learning situations. There were five sessions of training for each group (a collection of 20 sessions) marking the phase of intervention and four such sessions took place in a week to outline goals specific to each of the sessions. Each session lasted for an hour, extendable to one and half an hour regarding the level of awareness and rich information and interst of the participants. The research was in charge of deciding about final outline of the subjects raised in the meetings. Concurrently, the control group was controlled of not being aware of the training and information given to the experimental group. After intervention, the researcher again controlled the checklist for eventual evaluation. The researcher then identified the patients in whose body the experimental group nurses had placed intravenous line. The researcher carefully checked the position to be ensured of non-occurrence of catheter insertion complications. Then the researcher washed arms of the patients and removed catheter-specific dressing from their body, deciding the degree of phlebitis based on the instrument brought in the checklist. Then the researcher examined whether phlebit is present in the area of venipuncture within 72 hours from venipuncture. Eventually, to honor research ethics, the intervention phase educational resources were given to the control group nurses as well.

To meet the goals of the research, the structured training class was decided to be held in five sessions to include the following subjects: Anatomy of skin; body composition and liquids; types of injectable solutions; venipuncture principles; types of catheterization; the measures 
nurses were to be adopted for venipuncture and different kinds of phlebitis.

The collected data were analyzed on descriptive statistics (including mean, standard deviation, frequency and percentage) and independent t-test, paired t-test, and chi-square through the SPSS software version 25 .

\section{Results}

The study sample size included 400 patients: 200 patients were assigned to the control group while 200 to the experimental group $(50 \%$ of the samples were male and $50 \%$ were female). Out of 200 control group patients, $99(49.5 \%)$ had been admitted to the men's internal medicine ward and $101(50.5 \%)$ to the women surgery ward. This is while, the experimental group included 200 patients: $99(49.5 \%)$ of the patients had been admitted to the women internal medicine ward and $101(50.5 \%)$ were hospitalized in the men surgery ward. Table 1 shows the frequency distribution and percentage of the patients' demographic variables placed in the two control and experimental groups.

Table 1: A Comparison of the Frequency Distribution and Percentage of the Qualitative Demographic Features of the Control and Experimental Group Patients

\begin{tabular}{|c|c|c|c|c|c|c|}
\hline \multirow{2}{*}{ Variable } & \multirow{2}{*}{ Classes } & \multicolumn{2}{|c|}{ Control Group } & \multicolumn{2}{|c|}{ Experimental Group } & \multirow{2}{*}{ Test } \\
\hline & & Number & Percent & Number & Percent & \\
\hline \multirow{3}{*}{ Age } & 20-30 Years Old & 53 & 26.5 & 68 & 34 & \multirow{3}{*}{$\begin{array}{c}\mathrm{X}^{2}=2.708^{*} \\
\mathrm{df}=2 \\
\mathrm{p}=0 / 258\end{array}$} \\
\hline & $31-40$ Years Old & 44 & 22 & 41 & 20.5 & \\
\hline & 41-50 Years Old & 103 & 51.5 & 91 & 45.5 & \\
\hline \multirow{2}{*}{$\begin{array}{l}\text { Venipuncture } \\
\text { Side }\end{array}$} & Right & 140 & 70 & 107 & 53.5 & \multirow{2}{*}{$\begin{array}{c}\mathrm{X}^{2}=11.527^{*} \\
\mathrm{DF}=1 \\
\mathrm{p}=0 / 001\end{array}$} \\
\hline & Left & 60 & 30 & 93 & 46.5 & \\
\hline \multirow{2}{*}{$\begin{array}{l}\text { Dominent } \\
\text { Hand of the } \\
\text { Patient }\end{array}$} & Right Handed & 164 & 82 & 151 & 75.5 & \multirow{2}{*}{$\begin{array}{c}\mathrm{X}^{2}=2.525^{*} \\
\mathrm{DF}=1 \\
\mathrm{p}=0 / 112\end{array}$} \\
\hline & Left Handed & 36 & 18 & 49 & 24.5 & \\
\hline \multirow{3}{*}{$\begin{array}{l}\text { Angiocut } \\
\text { Insertion } \\
\text { Location }\end{array}$} & Hand Dorsum & 55 & 27.5 & 43 & 21.5 & \multirow{3}{*}{$\begin{array}{c}\mathrm{X}^{2}=2.193^{*} \\
\mathrm{df}=5 \\
\mathrm{p}=0.334\end{array}$} \\
\hline & Forearm & 66 & 33 & 67 & 33.5 & \\
\hline & $\begin{array}{l}\text { Antecubital } \\
\text { Fossa }\end{array}$ & 79 & 39.5 & 90 & 45 & \\
\hline \multirow{4}{*}{$\begin{array}{l}\text { Angiocut } \\
\text { Type }\end{array}$} & Pink-Vitro & 64 & 32 & 69 & 34.5 & \multirow{4}{*}{$\begin{array}{c}\mathrm{X}^{2}=15.127^{*} \\
\mathrm{df}=3 \\
\mathrm{p}=0.002\end{array}$} \\
\hline & Blue-Vitro & 18 & 9 & 31 & 15.5 & \\
\hline & GreenVax & 55 & 27.5 & 68 & 34 & \\
\hline & PinkVax & 63 & 31.5 & 32 & 16 & \\
\hline \multirow{4}{*}{$\begin{array}{l}\text { Type of } \\
\text { Serum }\end{array}$} & Normal Saline & 28 & 14 & 36 & 18 & \multirow{4}{*}{$\begin{array}{c}\mathrm{X}^{2}=3.834^{*} \\
\mathrm{DF}=3 \\
\mathrm{p}=0.280\end{array}$} \\
\hline & Dextrosaline & 25 & 12.5 & 24 & 12 & \\
\hline & Dextro Water & 23 & 11.5 & 13 & 6.5 & \\
\hline & $\begin{array}{l}\text { Normal Saline } \\
\text { and Dextrosaline }\end{array}$ & 124 & 62 & 127 & 63.5 & \\
\hline
\end{tabular}

\section{*Chi-Square Test}

Table 1 shows that the control and experimental groups did not have any difference of significant in terms of age, patient's dominant hand, place of angiocut insersion, and the type of serum used. Speaking the other way, the experimental and control groups were homogeneous ( $p>0.05)$. However, there was difference of statistical significance between the two groups in terms of the venipuncture side and the type of angiectomy.
Additionally, based on the data illustrated in Table 2, the risk of phlebitis incidence in the control group was $57.5 \%$ while it was $28.5 \%$ in the experimental group. Therefore, there is a relative danger $R \cdot R=\frac{0.285}{0.575}=0.49$ at work with confidence interval of 95 percent (falling in an area between 0.42 and 0.67 ). Therefore, training seems to check the risk of phlebitis occurrence. 
Baqaei R, Khalkhali HR, Rezaeifar P...... 47

Table 2: Chi-Square Test Results for Eruption of Phlebitis in the Experimental and Control Groups

\begin{tabular}{|c|c|c|c|c|c|c|}
\hline Variable & \multirow{2}{*}{$\begin{array}{c}\text { Classification } \\
\text { of Subjects }\end{array}$} & \multicolumn{2}{|c|}{ Control Group } & \multicolumn{2}{|c|}{ Experimental Group } & Test \\
\hline \multirow{4}{*}{ Phlebitis } & & Number & Percentage & Number & Percentage & \multirow{4}{*}{$\begin{array}{c}\mathrm{X}^{2}=34.313 \\
\mathrm{df}=1 \\
\mathrm{p} \leq 0.0001\end{array}$} \\
\hline & $\begin{array}{c}\text { Subjects With } \\
\text { Phlebitis }\end{array}$ & 115 & 57.5 & 57 & 28.5 & \\
\hline & $\begin{array}{l}\text { Subjects Without } \\
\text { Phlebitis }\end{array}$ & 85 & 42.5 & 143 & 71.5 & \\
\hline & $\begin{array}{c}\text { Total Number of } \\
\text { Subjects }\end{array}$ & 200 & 100 & 200 & 100 & \\
\hline
\end{tabular}

The study findings illustrated in Table 3 show that there is a significant difference in the control and experimental groups' scores in terms of severity of phlebitis occurring among the admitted patients after an intervention. In other words, with 95th percentile confidence, it should be claimed that structured nursing education programs was effective in severeness of phlebitis hitting the admitted patients to the extent that the rate declined in the case of the experimental group compared to the control one.

Table 3: Results of Independent T-Test to Check Severity of Phlebitis among the Control and Experimental Groups after Intervention

\begin{tabular}{|c|c|c|c|c|c|c|c|c|c|}
\hline \multirow[b]{2}{*}{ Group } & \multicolumn{4}{|c|}{ Descriptive Statistics } & \multicolumn{2}{|c|}{ Levin Test } & \multicolumn{3}{|c|}{ Independent T-Test } \\
\hline & Number & Mean & SD & SEM & $\mathbf{F}$ & $\begin{array}{c}\text { Level of } \\
\text { Significance }\end{array}$ & t & df & $\begin{array}{c}\text { Level of } \\
\text { Significance }\end{array}$ \\
\hline $\begin{array}{l}\text { Control } \\
\text { Group }\end{array}$ & 200 & 1.38 & 1.09 & 0.077 & 1613 & & & & 0.0001 \\
\hline $\begin{array}{c}\text { Experimental } \\
\text { Group }\end{array}$ & 200 & 0.760 & 1.04 & 0.074 & 1.613 & 0.205 & 5.840 & 398 & 0.0001 \\
\hline
\end{tabular}

\section{Discussion}

This study showed that the incidence of phlebitis in the experimental group patients was lower than in the control group. Karadeniz et al. (2014) indicated in Turkey that though having enough information on venipuncture and phlebitis, nurses often have difficulty in using and implementing the information, having poor function [23]. The finding is in vein with this study results.

The study results also pointed to the fact that phlebitis was highly prevalent in the control group. Tazakori et al. (2014) in a study noted that regarding high rate of occurrence of phlebitis, necessary education and training need to be offered in connection with appropriate insersion of catheter in a bid to check incidence of phlebitis [24]. This is in vein with results of this study.

Furthermore, Alirmani (2008) in a study claimed that the time period for implanting angiocut seemed to be the most important factor leading to different degrees of phlebitis as patients received antibiotics. Cutting the period for angiocut insersion from 72 hours to 48 hours and less seems minimizing rate of phlebitis incidence, which is one of the factors causing hospital inflection [11]. That is in line with findings of this research to some extent.

This study's results indicated that there was a significant difference between the rate of incidence of phlebitis in the experimental group patients compared to that in the control group. In this regard, Madar-Shahian et al. (2010) claimed that evidence-based trainings are as effective as traditional trainings in ensuring clinical care. They said such trainings will also upgrade the recepients' knowledge, skills and high-quality care [25].

Results of this research indicated high percentage of phlebitis severity in the patients lying in the control group. Borzou et al (2009) indicated that the highest rate of phlebitis incidence was observed in 48 hours after catheter insersion [10]. Furthermore, Jaafarnejad et al. proved that majority of patients suffering from phlebitis had catheter in their body for more than two days. Their findings showed that rate of phlebitis occurrence significantly correlated with the time catheter had been placed in their vein and also with consumption of specific medicine and antibiotics [26], which is relatively in vein with the findings of present study. 
Of course, some studies suggest that besides profession and experience of nurses, there might be other factors at work in eruption of phlebitis. Taghi Nejad et al. (2005) showed that rate of occurrence of phlebitis and local infection in the group treated with betadine was less observed than in the group treated by alcohol [27]. This study findings were in favor of structured nursing education programs, proving their effectiveness as rate of phlebitis incidence was lower in the experimental group patients than the control group ones. Oziazikioglu et al. (2008) in Turkey in a study indicated that education of nurses is effective in checking venous complications, including phlebitis [28]. Zhang Xia et al. (2011) in China also proved that nurse training before insersion of angio cut in patients subject to chemotherapy was effective in decreasing rate of phlebitis incidence [29]. Moreover, Kanishka et al (2013) in India showed that 8.54 percent of patients suffered from phlebitis. Majority of patients contradicted degree 1 phlebitis. The experimental group in that study had undergone structured training well upgrading their knowledge and practice significantly to control and prevent incidence of phlebitis [30]. The study is in conformity with the results of this study.

The results showed that the rate of phlebitis in the control group was higher than that in the experimental group. This signifies that structured education was influential in minimizing the risk of phlebitis. To this end, Dink et al. (2015) proved in a study that training would be effective in upgrading nurses' knowledge and performance, while contributing to promotion and improvement of the performance of the personnel in charge of catheter care, thus leading to less bacterial catheter colonization [31]. The finding is in agreement with the results of this study.

Alike other studies, the study at hand faced a number of limitations, which should be taken into consideration when generalizing its findings. Hope that researchers will consider and judge this study with respect to the limitations on the way and that likely limitations will be lifted when attempting to design future studies. The present study just concerned two groups, namely nurses and patients admitted to the internal medicine and surgery wards of Iranian city of Mahabad. This is believed to limit generalizability of the findings. In other words, results of this study might not be generalized to nurses and patients in other contexts. The results of this study are crosssectional: The data were collected in a juncture of the year, expected to be different in other times of the year; so, the research could not control the variable 3) Among other limitations of this study were nurses' psychological condition at work and their care for the patients, which might have been affected their behavior. That was beyond the researcher's control 4) To cite other limitations of the study, reference should be made to the type of angiectomy selected by the nurses for different groups under this study. Controlling the variable was not possible for the researcher for being invisibly assessing likely phlebitis occureence in the wards.

The complications and risks of phlebitis occurrence as a result of venus injections to the patients would delay their treatment and recovery, inflicting delayed and irreversible complications. Therefore, nurses are recommended to raise level of their awareness of the dangers, symptoms and signs to check such bitter incidents and events. Regarding their key and vital role in implementing guidelines to care patients, nurses should be updated and kept abreast of the latest in clinical care and update their clinical knowledge. The researcher hopes that the study findings will afford promotion of patients' health standards and empower nurses, while serving their education.

\section{Acknowledgments}

The researchers hereby express their gratitude to the Honorable Vice-Chancellor for Research and Technology of Urmia University of Medical Sciences and the University's Nursing Faculty for their financial support. Furthermore, directors and officials of Imam Khomeini Hospital of Mahabad and dear nurses and patients are appreciated for their sincere cooperation and active participation in this research.

\section{Conflict of interest}

The authors of this article confirm that there is no conflict of interest with regards to present study.

\section{References}

1. Huckleberry MJ; and Wilson D. Wong's nursing care of infant and children9th ed. St Louis Missouri: Mosby. 2011. 210-55. 
2. Soifer NE1, Borzak S, Edlin BR, Weinstein RA. Prevention Of Peripheral Venous Catheter Complication With An Intravenous Therapy Team: a randomized controlled trial. Arch Intern Med. 1998; 158(5): 473-77.

3. Kohl DB. Exploration of the patterns of microbial colonization of intravascular devices in severely ill patient. $[\mathrm{PhD}$ thesis]. Australian: University of Tasmania. 2011: 33-38.

4. Behrman RE. Klieg man, RM. Jason, HB. Nelsons text book of pediatrics. $18^{\text {th }}$ ed. Philadelphia: WB. Saunders co. 2017: 458-488.

5. Foster L,Wallis $m$,Paterson B, Tames H. A Descriptive study of peripheral intravenous catheters in patients admitted to a unit in one Australian hospital. J Infus Nurs. 2002. 25(3): 159-67.

6. Macklin D. Phlebitis: A painful complication of peripheral IV catheterization that may be prevented. Am J Nurs. 2003; 103(2): 55-60.

7. Nettina MSN ANP-BC, Sandra M.. The Lippincott manual of Nursing Practice. $7^{\text {th }}$ ed. Maryland: Lippincott Co. 2013: 82-120.

8. Helm RE, Klausner JD, Klemperer JD, Flint LM, Huang E. Accepted but unacceptable: peripheral IV catheter failure. J Infus Nurs. 2015; 38(3): 189-203.

9. Poormohamadi M, Farsi Z, Rajai N. The Effect Of 2\% Chlorhexidine Gluconate Solution On Prevention Of Phlebitis Related To Peripheral Venous Catheter In Patients Hospitalized In Cardiac Care Units Of A Military Hospital. Military Caring Sciences. 2017; 4(1): 19-29. [In Peresian]

10. Lee W-L, Chen H-L, Tsai T-Y, et al. Risk Factors For Peripheral Intravenous Catheter Infection In Hospitalized Patients: A Prospective Study Of 3165 Patients. Am J Infect Control. 2009; 37(8):683-86.

11. Aliramaie N. The Survey On Phlebitis From Venous Catheter In Patients Haspitalized In Icu In Besat Hospital In Sanandaj. J Urmia Nurs Midwifery Fac. 2008; 6 (3) :124-127

12. Khawaja HT, James J. Survival of peripheral intravenous infusion. BMJ. 1992; 304: 1053-54.

13. Borzou SR, Zamanparvar AR, Farmani A, Saremi E, Zandiyeh M, Salavati M. Assessment of Shelf Life of Intravenous Catheters with Incidence of Superficial Phlebitis in Hospitalized Patients. Avicenna J Nurs Midwifery Care. 2009; 17(12): 63-73. [In Peresian]
14. Stokowski G, Steele D, Wilson D. The use of ultrasound to improve practice and reducecomplication rates in peripherally inserted central catheter insertions: final report of investigation. J Infus Nurs. 2009; 32(3): 145-55. 15. Hinkle JL, Cheever KH. Brunner and Suddarth's textbook of medical-surgical nursing. $13^{\text {th }}$ ed. Philadelphia: Lippincott Williams \&Wilkins; 2013: 282.

16. Royal College of Nursing. Standards for infusion therapy. $3^{\text {th }} \mathrm{ed}$. London: Royal College of Nursing; 2010.

17. Monreal M. Infusion phlebitis in patient with acute pneumonia: A Prospective study. chest: 1999: 115 (6): 1576-80.

18. Evans, David. "Management of peripheral intravascular devices." Best Practice, 1998, 2(1): 33.

19. Suzanne CS, Brenda GB, Janice LH, Cheever KH. Brunner \& Suddarth's Textbook Of Medical Surgical Nursing. $11^{\text {th }}$ ed. Philadelphia: JB Lippincotte Company; 2008: 447-521.

20. Mirzabeygi G, Sanjari M, Salemi S, Babaei F, Kheradmand M. The Necessity for Specialty Education in Nursing MS Program: Viewpoints of the Faculty Members of School of Nursing and Midwifery in Iran. Iran J Med Educ. 2009; 9(3): 263-70. [In Peresian]

21. Kadam A, Shinde MB. Effectiveness of Structured Education on Caregiver's Knowledge and Attitude Regarding Colostomy Care. Int J Sci Res. 2014; 3(4): 586-93.

22. Black JM, Hawks JH. Medical surgical nursing: Clinical management for positive outcomes. $8^{\text {th }}$ ed. St. Louis: Westline Industrial Drive; 2009.

23. Karadeniz G, Kutlu N, Tatlisumak E, Ozbakkaloglu B. Nurses' knowledge regarding patients with intravenous catheters and phlebitis interventions. J Vasc Nurs. 2003; 21(2): 48-49.

24. Kalani Z, Pourmovahed Z, Vaezi A A, Vaziri $S$ F.Assessing the Risk Factors of Phlebitis Incidence Related to Peripheral Catheter An Analytical Study.jhosp.2015; 14(3) :93-99. hosp.tums.ac.ir/article-1-5484-en.html.

25. Madarshahian F, Hassanabadi M, Khazayi S. Effect of evidence-based method clinical educationon patients care quality and their satisfaction. Educ Strategy Med Sci. 2012; 4(4): 189- 93. [In Peresian] 
26. Jafanejad M, FaniSaberi L, Motlagh F,Zare A, Tahak S. Evaluation of intravenous catheter phlebitis and its related factors in hospitalized patients in Neka hospitals in 2016. $6^{\text {th }}$ National Conference on Health Promotion Strategies and Challenges Focused on community-based care; Sari. 2016.

27.Taghinezhad $\mathrm{H}$,Asadizaker $\mathrm{M}$, Tabesh $\mathrm{H}$. Comparative study of effects of Alchol and Betadine as sterilization on complication of centeral venous catherteriztion. Ilam med Sci Univ. 2004; 13(4): 10-16. [In Peresian]

28. Ozyazicioglu N, Arıkan D. The effect of nurse training on the improvement of intravenous applications. Nurse Educ Today. 2008; 28: 17985.
29. XuehuaZ, XiufenW. Nursing intervention of patients with phlebitis induced by peripherally inserted central catheter and its evaluation[J].Chinese Nursing Research.2006;17. en.cnki.com.cn

30. Kanishka G, Muninarayanappa B. Effectiveness of structured teaching program on knowledge and practices of staff nurses on prevention of intravenous cannulae complications. Arch Med Health Sci. 2013; 1(2): 115-19.

31. Dinc L, Erdil F. The efectiveness of an educational intervention in changing nursing practice and preventing catheter-related infectionfor patients receiving total parenteral nutrition. Int J Nurs Stud .2000; 37(5): 371-79. 